\title{
Mesoscale geographical patterns in the distribution of pandalid shrimps Plesionika spp. in the Western Mediterranean
}

\author{
Aina Carbonell ${ }^{1, *}$, Miquel Palmer ${ }^{2}$, Pere Abelló $^{3}$, Pedro Torres ${ }^{4}$, R. Alemany ${ }^{1}$, \\ Luis Gil de Sola ${ }^{4}$ \\ ${ }^{1}$ Centro Oceanográfico de Baleares (Instituto Español de Oceanografía), Moll de Ponent s/n, 08039 Palma de Mallorca, Spain \\ ${ }^{2}$ Instituto Mediterraneo de Estudios Avanzados (CSIC-UIB), Instituto Med. de Est. Avanz, C/Miquel Marques 21, \\ 07190 Esporles, Spain \\ ${ }^{3}$ Instituto de Ciencias de Mar (CSIC), Passeig Maritim de la Barceloneta 34-49, 08003 Barcelona, Spain \\ ${ }^{4}$ Centro Oceanográfico de Fuengirola (Instituto Español de Oceanografía), Puerto Pesquero s/n, 29640 Fuengirola, Spain
}

\begin{abstract}
Six bottom-trawl cruises, undertaken in spring 1994 to 1999 along the Spanish Mediterranean coastline, sampled pandalid shrimps from 30 to $800 \mathrm{~m}$ depth. Data analysis yielded a description of the distribution patterns of the 4 most common species (Plesionika heterocarpus, P. martia, P. gigliolii, $P$. edwardsi) over an area of $45331 \mathrm{~km}^{2}$. We analysed abundance of juveniles and adults by partial correspondence analysis (pCCA) in order to determine the effect on distribution of depth (as an overall estimate of temperature, salinity, turbidity and other variables), time (among-survey variability) and space (geographical location). The main null hypothesis we explicitly evaluated is that species composition remains constant along the Spanish Mediterranean coastline after controlling for depth and time. A significant (8.2\%) effect of geographical location was found. Hauls located in the central zone of the sampling cruises (Valencia: Ibiza Channel) showed an intermediate relative abundance of all species. By contrast, the samples from northern and southern zones showed a large relative abundance of $P$. martia and $P$. heterocarpus, respectively. This pattern may be related to environmental specificity of the hydrodynamic conditions in the Ibiza Channel, dynamic topography characteristics linked to the canyons in the North Catalan zone, and surface production inputs, as found in the North Alborán zone (southern zone), where the main species ( $P$. heterocarpus) exhibited the shallowest bathymetric distribution. Although discrimination between depth preferences of juveniles and adults (with adults being located deeper) is already known on a local scale, our results extend this pattern to the entire Spanish Mediterranean coastline and across all the species studied.
\end{abstract}

KEY WORDS: Multivariate analysis · Species abundance-environment relationships $\cdot$ Spatial patterns · Mapping $\cdot$ Pandalidae $\cdot$ Crustacea

Resale or republication not permitted without written consent of the publisher

\section{INTRODUCTION}

Comprehensive knowledge of community structure of decapod crustaceans suggests that a number of traits related to the community structure might change at the regional scale (Maynou \& Cartes 2000). These changes have been attributed to trophic factors (surface production and food web structure), and changes in vertical zonation would be one of the traits affected (Maynou \& Cartes 2000).
Despite these regional changes, congeneric assemblages of pandalid shrimps usually show partitioned bathymetric space, each species occurring at a preferred depth interval. The genus Plesionika (A. M. Edwards, 1883) (Decapoda, Caridae, Pandalidae) is a typical example. Vertical-layered distribution by species has been previously described (e.g. Company \& Sardà 1997, Carbonell \& Abelló 1998, Puig et al. 2001). Considering the 4 commonest species in the Western Mediterranean, P. heterocarpus (Costa, 1871) 
is favoured in shallow waters (100 to $400 \mathrm{~m}), P$. edwardsi (Brandt, 1851) and P. gigliolii (Senna, 1903) span from 200 to 500 m, and P. martia (A. M. Edwards, 1883 ) is mainly located between 400 and $600 \mathrm{~m}$ (Company \& Sardà 1997, Carbonell \& Abelló 1998).

Differences in depth preferences between juveniles and adults of some Plesionika species have also been described (Company \& Sardà 1997, Carbonell \& Abelló 1998). Results show that adults tend to be found deeper than juveniles in 2 species, $P$. heterocarpus and $P$. martia, while there is no clear differentiation for the other 3 species: P. gigliolii, P. edwardsi and P. acanthonotus (Company \& Sardà 1997). However, data from multiple sites indicate that $P$. edwardsi also displays a significant relationship between body size and depth: larger shrimps are found at deeper depths (Carbonell \& Abelló 1998).

In this study, we analyse the data from 6 yearly sampling surveys with a research vessel, covering more than $45000 \mathrm{~km}^{2}$. In total, 613 hauls were performed and 171534 individuals were sampled. The large spatial extension of the sampling programme allowed us to analyse the effects of the geographical location at the regional scale. In addition, the effects of space itself are also considered. Populations and assemblages are spatial objects in the sense that their structure also depends on the spatial context that they inhabit (e.g. Roa \& Tapia 2000). Spatially structured assemblages (or populations) of the shrimps studied may emerge from spatially structured environmental forces (e.g. temperature variation linked to latitude) and/or from internal forces (e.g. population dynamics). The withinand between-species distribution patterns described above suggest that both internal (i.e. vertical splitting between juveniles and adults) and environmental forces (i.e. latitudinal temperature gradient and other spatially structured environmental variables) might play a role. Therefore, the analytical approach we used considers 3 data sets: the species (response variables), the explanatory environmental variables, and the geographical location itself. Accordingly, the reasons for variation in species composition can be dissected into (1) purely environmental, (2) spatially structured environmental, and (3) purely spatial (Legendre \& Legendre 1998). By mapping these fractions it is possible to elucidate the factors affecting the patterns of variation of pandalid shrimp assemblages. The main null hypothesis we explicitly evaluated is that species composition remains constant along all of the Spanish Mediterranean coastline after controlling for depth and year. Moreover, we searched for general patterns of depth preferences at both intra- (juveniles versus adults) and interspecific levels.

\section{MATERIALS AND METHODS}

Sampling domain and sampling program. The study area encompassed the continental shelf and slope between the Straits of Gibraltar and Cape Creus (approx. $1200 \mathrm{~km}$ ). Samples were carried out between 35 and $786 \mathrm{~m}$ depth. Depth-stratified random sampling was performed in spring 1994 to 1999 using an experimental bottom trawl GOC 73 (Grande Ouverture avec Côtés), which is a wide-opening trawl made of 4 panels with a 2.5-3 m vertical opening, a $28.2 \mathrm{~m}$ footrope and a $20 \mathrm{~mm}$ cod end mesh size stretched (Bertrand et al. 2000, 2002). Hauls performed at depths of less than $200 \mathrm{~m}$ had a duration of $30 \mathrm{~min}$; those performed deeper had a duration of $60 \mathrm{~min}$. The starting point of a haul determined its position (Digital Global Positioning System, DGPS). Haul depth was assumed as the mean depth between the start and the end. The maximum difference between starting and ending depth was $5 \%$. Depth was determined by an echosounder. The length trawled during a haul (after normalisation by 60 min trawling time for all samples) was $2587 \pm 406 \mathrm{~m}$ (average \pm standard deviation). A total number of 613 hauls were carried out (Fig. 1). Hauls rendering individuals of the considered species (335 hauls) are shown in Fig. 1a. The number of individuals, depth ranges and weighed mean depth were determined. Abundance values were standardised to number of individuals per hour of trawling. All individuals, or a representative sample, were sexed and measured (cephalothorax length, CL, in $\mathrm{mm}$, accurate to $0.1 \mathrm{~mm}$ ). The variables analysed here were the number of adults and the number of juveniles. Determination of the maturation stage for females was done visually during sampling on board, and 4 stages were considered: (I) immature, with no ovary colouration and no eggs in pleopods; (II) maturing, with coloured ovaries and eggs in pleopods; (III) close to spawning, with eyes visible in embryos; (IV) post-spawning, with the rest of the eggs in pleopods and coloured ovaries. Sexual maturity curves were inferred from the normal accumulated curve of the percentage by size of ovigerous females versus total females (inmature and mature). The size at first maturity for females $\mathrm{CL}_{50}$ was obtained from the Gompertz equation, assuming the same size for both sexes.

Statistical multivariate analysis. Partial canonical correspondence analysis (pCCA) allowed partitioning of the variation of variables of interest (i.e. species abundance matrix) as linear combinations of some subsets of explanatory variables (e.g. Legendre \& Legendre 1998). Here we considered 3 subsets of explanatory variables: environmental, spatial, and time-related. Environmental variables (denoted by $\boldsymbol{X}$ ) were summarised by the single depth vector ( $\mathrm{m}$ below sea level) as an overall estimate of temperature, salinity, and other vertically structured variables. The spa- 

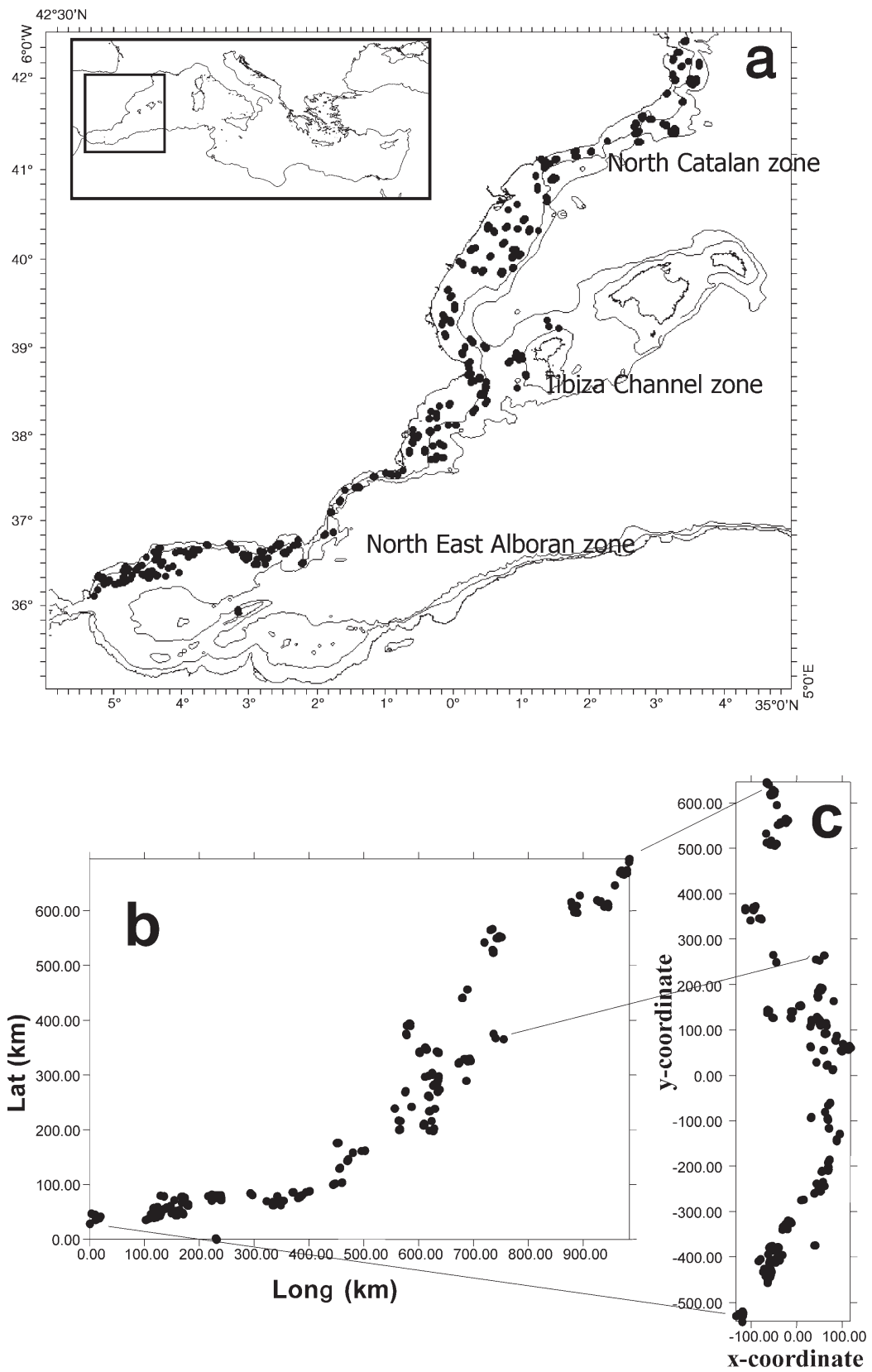

Fig. 1. Location of sampling sites. A conventional map (a) helps to interpret the significance of $x / y$-coordinates in (b) $\mathrm{km}$-transformed geographic data from an arbitrary origin and (c) km-transformed and rotated data after principal component analysis. Long: longitude; Lat: latitude

formed coordinates was carried out using the same principle as trend surface analysis (e.g. Legendre \& Legendre 1998). The order of the polynomial equation to be used was found from trials of first $(x, y)$, second $\left(x^{2}, y^{2}, x y\right)$ and successive higherorder models. After the maximum explanatory power was reached, all nonsignificant terms were removed. Every step was performed by successive CCA runs using CANOCO 4 (ter Braak \& Smilauer 1998). The resulting combination of polynomial terms composed the matrix of spatial predictors (denoted by $\boldsymbol{W}$ ).

The sampling program spanned from 1994 to 1999. Each haul was coded by a set of dummy variables according to the year it was performed. Thus, there were 6 dummy variables (1 of them being a linear combination of the other 5). These time-related variables are denoted by $\boldsymbol{T}$.

Some CCA models were run in order to test the null hypothesis. First, we considered a general model including $\boldsymbol{X}$ (environment), $\boldsymbol{W}$ (space) and $\boldsymbol{T}$ (time). In response to the results obtained, some additional pCCAs (detailed below) were performed (i.e. certain subsets of explanatory variables were considered as covariables and their effects were controlled for): pCCAs were also performed using CANOCO. F-ratio significance of all CANOCO runs was assessed by 1999 permutations under the reduced model (ter Braak \& Smilauer 1998).

Mapping the fractions of variation on species composition: Geostatistics were used as a tool for evaluating the spatial variation of the sample scores obtained from different CCA runs. Variables measured at sites close to one another tend to be more similar than those measured farther away. Autocorrelation was assessed by inspection of semivariogram models. Semivariance is a function of similarity between values recorded in pairs of sample points separated by a lag distance; a

tial component of variation in species composition was modelled by forcing CCA to extract axes of variation that are related to latitude-longitude coordinates. Original geographic data (degrees-minutes) were first transformed to decimal system coordinates and later to $\mathrm{km}$ (by a factor of 1.852; Fig. 1b), and finally rotated by principal component analysis (covariance matrix; Fig. 1c). CCA on the species matrix of these transsemivariogram is the plot of variances reached at successive multiples of the lag distance. It provides information about processes occurring at different spatial scales and allows for the determination of certain parameters used for mapping (Legendre \& Legendre 1998, Roa \& Tapia 2000, Rossi \& Costantini 2000). Contour maps were obtained by kriging (Englund \& Sparks 1988). This geostatistical griding method tends to con- 
nect high points along a ridge. Cross validation compared the estimated map (based on the parameters obtained from the semivariogram model) and the observed values. Semivariograms, contour maps and cross validation were performed using Geo-EAS (Englund \& Sparks 1988).

\section{RESULTS}

\section{Preliminary analysis}

The total number of individuals surveyed during 6 consecutive years amounts to 171534. Total abundance of the species considered, as well as the observed vertical distributional ranges, are summarised in Table 1 . The size at first maturity for females $\left(\mathrm{CL}_{50}\right)$ for the 4 species is presented in Table 2.

In order to assess the importance of partial effects of space on species composition, we inferred the order of the polynomial combination of the $x / y$-coordinates (from Fig. 1c) with the best explanatory power. The best combination of polynomial terms was simply the $\boldsymbol{x}$-vector (variation explained $=5 \%, F$-ratio $=15.1, p<0.0005)$. Therefore, spatial effect was assumed to be summarised by the $x$-axis position from Fig. 1c (i.e. the matrix of spatial predictors is composed by the single vector, $\boldsymbol{x}$ ).

The first general CCA we performed tested a model composed of all 3 variable subsets (time-related, spatial, and environmental). Such a model explains $42.1 \%$ $(F$-ratio $=31.872, \mathrm{p}<0.0005)$ of the variability of the

Table 1. Plesionika spp. Number of individuals per hour of trawling. Number of samples (hauls) in which each of the species is present (n), depth range (maximum and minimum depth where a species was sampled along all of the geographical range considered) and weighted mean-depth of maximum abundance calculated as the centre of species distributions (GOC) are also indicated

\begin{tabular}{|lrrrrrrc|}
\hline Species & Juveniles & Adults & Total & $\mathrm{n}$ & $\begin{array}{c}\text { Depth } \\
\text { range }(\mathrm{m})\end{array}$ & $\begin{array}{c}\text { GOC } \\
\text { depth }(\mathrm{m})\end{array}$ \\
\hline Plesionika edwardsi & 2955 & 7627 & 10582 & 41 & $174-632$ & 355 \\
Plesionika gigliolii & 1767 & 14847 & 16614 & 90 & $243-681$ & 483 \\
Plesionika heterocarpus & 24309 & 97136 & 121445 & 124 & $46-461$ & 259 \\
Plesionika martia & 7315 & 15578 & 22893 & 148 & $267-786$ & 565 \\
\hline
\end{tabular}

Table 2. Plesionika spp. Size at first maturity $\left(\mathrm{CL}_{50}=\right.$ cephalothorax length in $\mathrm{mm}$ ), including standard deviation (SD) and sum of squares residual (SS). CL lower-mat: lowest CL size (mm) of females with coloured ovaries

\begin{tabular}{|lrccc|}
\hline Species & $\mathrm{CL}_{50}$ & SD & SS & CL lower-mat \\
\hline Plesionika edwardsi & 16.34 & 2.6398 & 0.7751 & 10.00 \\
Plesionika gigliolii & 8.33 & 1.1927 & 0.0111 & 7.80 \\
Plesionika heterocarpus & 10.16 & 1.0293 & 0.1900 & 8.50 \\
Plesionika martia & 15.58 & 2.0605 & 0.0222 & 10.00 \\
\hline
\end{tabular}

species abundance matrix (ln-transformed values). There were only 2 significant canonical axes (significance of canonical axes was calculated following ter ability explained by time (yr) seems to be smaller than that explained by depth and $x$-coordinate variables. The species pattern suggested by Fig. 2 is derived by projecting species location onto the variable arrows Legendre \& Legendre 1998). Regarding depth, the abundance of Plesionika martia is large at shallow waters. All 4 species display a clear between depth preferences of juveniles and adults (the latter located deeper). In respect of the $x$-coordinate, the relative abundance of $P$. gigliolii and $P$. edwardsi is larger toward the right of Fig. 1. This indicates a arger abundance towards the southeast in the zone of Ibiza Channel. The other 2 species tend to be more abundant in the opposite direction.

\section{Time-related effects}

The position of the 6 dummy variables corresponding to the time-related effects (i.e. among-year variability) could suggest some differences in species composition between 1994-1996 and 1997-1999. A pCCA of the species abundance matrix constrained by these 6 time-related variables, and using depth and $x$ coordinate as the covariable matrix, allowed us to test for a pure timerelated effect. Such an effect was found to be significant ( $F$-ratio $=2.2, \mathrm{p}=$ 0.0015) but small (explaining 3.4\% variance). Variance decomposition of the time-related effect on species composition is detailed in Table 3. The corresponding biplot (combined effects of time, depth and $x$-coordinate) does not reveal any clear trend (Fig. 3), and the temporal series available (6 yr) is not sufficient for formal analysis of a temporal trend. Moreover, amongyear differences seem to be general (without bias toward specific depth or spatial location) because nonsignificant interactions were found neither between time and depth nor between time and the $x$-coordinate (results not shown). 


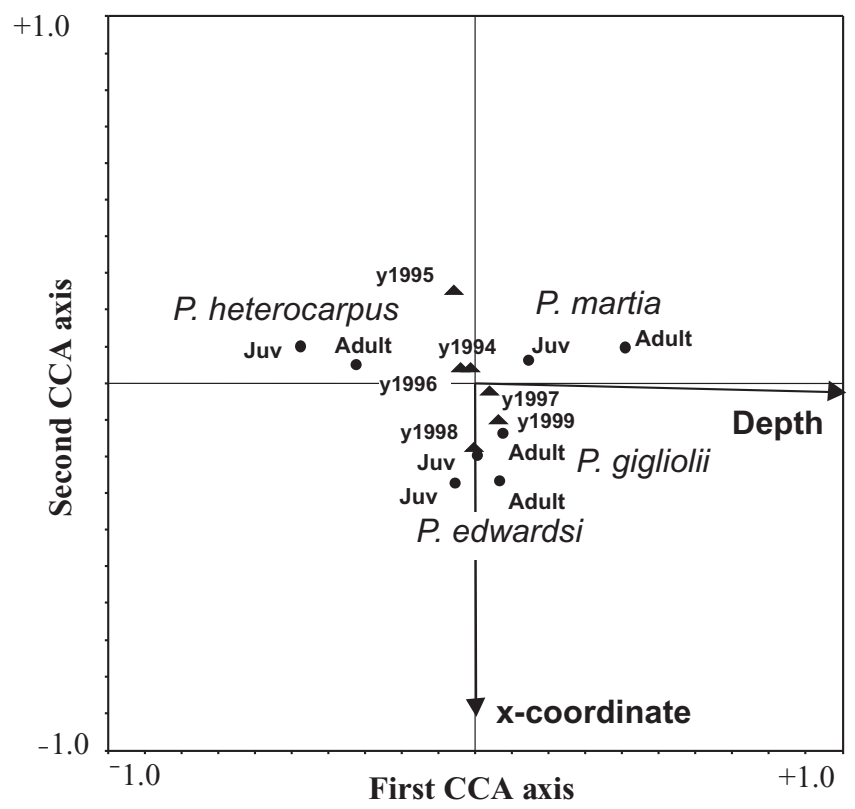

Fig. 2. Plesionika spp. CCA (canonical correspondence analysis) ordination biplot of the abundance data including all explanatory variables in the analysis. Species are denoted by a point. Qualitative variables (yr) are represented by triangles and quantitative variables by arrows. Ranking of the species along a quantitative variable is inferred by projecting the species onto the arrow representing the variable

\section{Combined effect of depth and $x$-coordinate (i.e. spatial location)}

In response to the results above, the time-related matrix $(\boldsymbol{T})$ was used as a covariable in a new analysis looking for variance decomposition between the $x$-coordinate and depth effects. The results of such variance decomposition are detailed in Table 4 . The considered effects (namely $x$-coordinate and depth) are highly significant $(\mathrm{p}<0.0005)$. The main effect is depth (explained variation $=34.8 \%$ ), while the variance explained by the $x$-coordinate is smaller $(5.2 \%)$.

Table 3. Plesionika spp. Variance decomposition of the effects (on species composition) of time versus depth and space. Partial CCAs allow an indirect estimation of the explained variance shared by time and other variables. Time itself explains a small but significant percentage of variance

\begin{tabular}{|lcccc|}
\hline Source & Variance & \% variance & $F$ & $\mathrm{p}$ \\
\hline Time (1) & 0.041 & 2.1 & 2.209 & 0.0015 \\
Shared 1-2 & 0.003 & 0.1 & & \\
Depth and Space (2) & 0.790 & 40.0 & & \\
Residual & & 57.8 & & \\
Total & 1.997 & & & \\
\hline
\end{tabular}

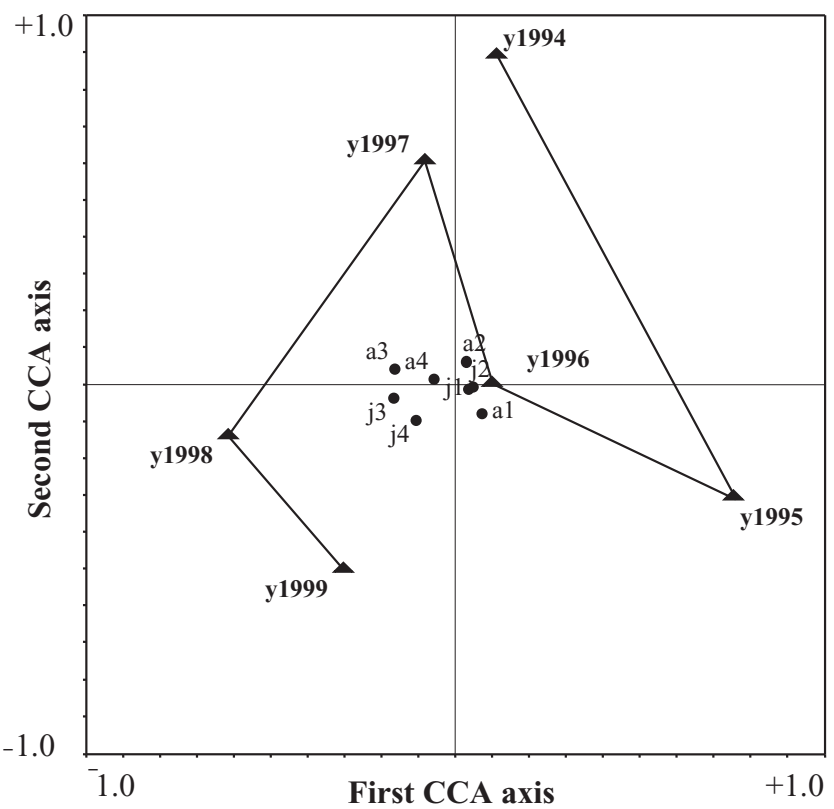

Fig. 3. Plesionika spp. Partial CCA (canonical correspondence analysis) ordination biplot of the abundance data with time being the only explanatory set of variables (depth and space are considered as covariables). Years are represented by triangles. The line indicates the temporal series. No clear temporal trend is evidenced. 1: P. martia; 2: P. heterocarpus; 3: P. edwardsi; 4: P. gigliolii; a: adults; j: juveniles

The pattern suggested by this analysis is essentially the same as revealed in Fig. 2. It should be noted that there are only 2 significant canonical axes. This is evidenced in Fig. 4, which shows the specific effects of depth.

\section{Mapping $x$-coordinate effects}

Two interesting points should be noted. First, shared variance explained by both depth and the $x$-coordinate is virtually $0 \%$. This fact is also evidenced in Fig. 2,

Table 4. Plesionika spp. Variance decomposition of the effects on species composition of depth and space ( $x$-coordinate from Fig. 1c). Both depth and space explain a significant percentage of the variance. Moreover, the shared percentage of variance between depth and space is virtually zero

\begin{tabular}{|lrrrc|}
\hline Source & Variance & \% variance & \multicolumn{1}{c|}{$F$} & $\mathrm{p}$ \\
\hline Depth (1) & 0.041 & 34.8 & 31.872 & $<0.0005$ \\
Shared 1-2 & -0.001 & 0.0 & & \\
Space (2) & 0.103 & 5.2 & 27.498 & $<0.005$ \\
Residual + Time & 1.185 & 59.2 & & \\
Residual & 1.143 & 57.8 & & \\
Total & 1.997 & & & \\
\hline
\end{tabular}




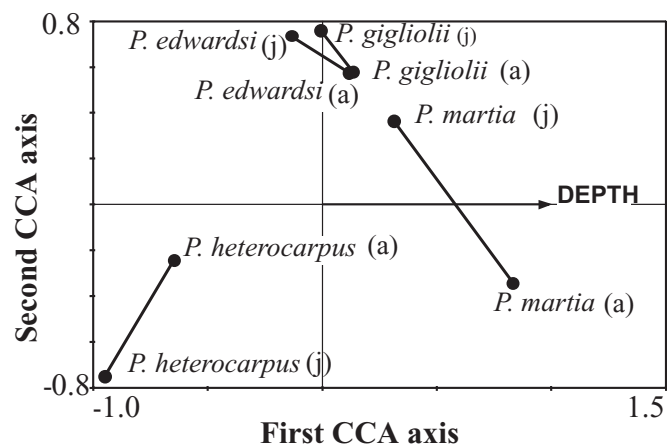

Fig. 4. Plesionika spp. Partial CCA (canonical correspondence analysis) ordination biplot of the abundance data with depth being considered as the explanatory set of variables (time and space are left as covariables). Ranking of the species along depth is inferred by projecting the species onto the arrow representing the variable. Adults (a) are located deeper than juveniles (j). Species are distributed along the depth gradient

where the vectors representing these variables are orthogonal. Second, the vector corresponding to depth is virtually on top of the first canonical axis, and the vector representing the $x$-coordinate is located on the second canonical axis. As a consequence, sample scores for the second canonical axis can be interpreted as the variance associated with the (geographic) $x$-coordinate. These sample scores have been analysed using geostatistical methods. First, a semivariogram was constructed in order to detect and model the extent of autocorrelation. The observed omni-directional variogram was adjusted (by eye) to a spherical model (parameters used: nugget effect $=0.1$, sill $=0.35$, range $=$ $30 \mathrm{~km}$ ). Cross validation of such a model did not show spatial bias of residuals. These parameters were used for mapping the scores corresponding to the second canonical axis. Therefore, the resulting map can be viewed as a spatial representation of the $x$-coordinate effect on species composition. This map is shown in Fig. 5b. Dark areas at the right correspond to high values on the second canonical axis. These high scores, in turn, imply high relative abundances of Plesionika gigliolii and $P$. edwardsi. Note that the $x$-axis on the map nearly corresponds to a southeast direction (Fig. 5c).

\section{DISCUSSION}

\section{Spatial patterns}

CCA linked to geostatistical methods (semivariograms and kriging) emerges as a powerful tool for interpreting the complex data sets commonly generated when meso- or large-scale ecological phenomena are studied (e.g. Legendre \& Legendre 1998). The case presented here is an example of its use because the relationship between environmental variables and species composition can be potentially obscured by among-sample variability ( 0 to more than 10000 individuals) and spatial autocorrelation.

Different goals can be achieved using CCA and geostatistics. Here we emphasise the description of purely spatial patterns. This approach can be considered descriptive because it points out the spatial structure of the 'residual variance' (i.e. the variance remaining when the effects of environmental variables have been accounted for). The resulting maps should be used for identifying additional environmental variables that explain the spatial pattern found (Legendre \& Legendre 1998).

The spatial pattern evidenced by CCA and geostatistics is characterised by a central zone (Valencia and Ibiza Channel) with a specific species assemblage. The northern and southern zones (e.g. Northern Catalan zone and Northern Alborán zone) show unexpectedly similar Plesionika assemblages, well differentiated from the central zone mentioned above. While the overall CCA analysis (including depth, time and space) accounted for $42 \%$ of variance of species abundance (Table 3), the unexplained variability of species abundance seems to display no spatial structure. Such an assessment was based on the map of the scores corresponding to the first non-canonical axis (explaining $21.5 \%$ ). This map (not shown) was obtained using the same geostatistical methods described above. Assuming no spatial structure of this remaining variance, it should be inferred that the spatial pattern is related to local environmental variables. One plausible example of these variables could be small-scale topographic specificities (e.g. canyons have been demonstrated to have some effects on species composition; Cartes et al. 1994). Other possible variables could be bottom specificities (within a general muddy bottom), such as sediment features related to feeding macrobenthic assemblages and biogenic structures (Gerino et al. 1995), or to the sedimentation rate (Zuo et al. 1997).

Another (not necessarily exclusive) explanation is also plausible: oligotrophy is a clear trend in the middle zone (Ibiza Channel) of the Western Mediterranean, while the upwelling in the Northwestern Alborán Sea and higher productivity by river discharge in the Northern Catalan zone are determinant processes at the other 2 zones. In this sense, a large biomass present in the Alborán zone is related to a large abundance of Plesionika heterocarpus, the shallowest species, while P. martia (the deepest species) is dominant at the Northern Catalan area. A specific assemblage may coexist more effectively in the central zone using low production inputs, while in the northern and southern 

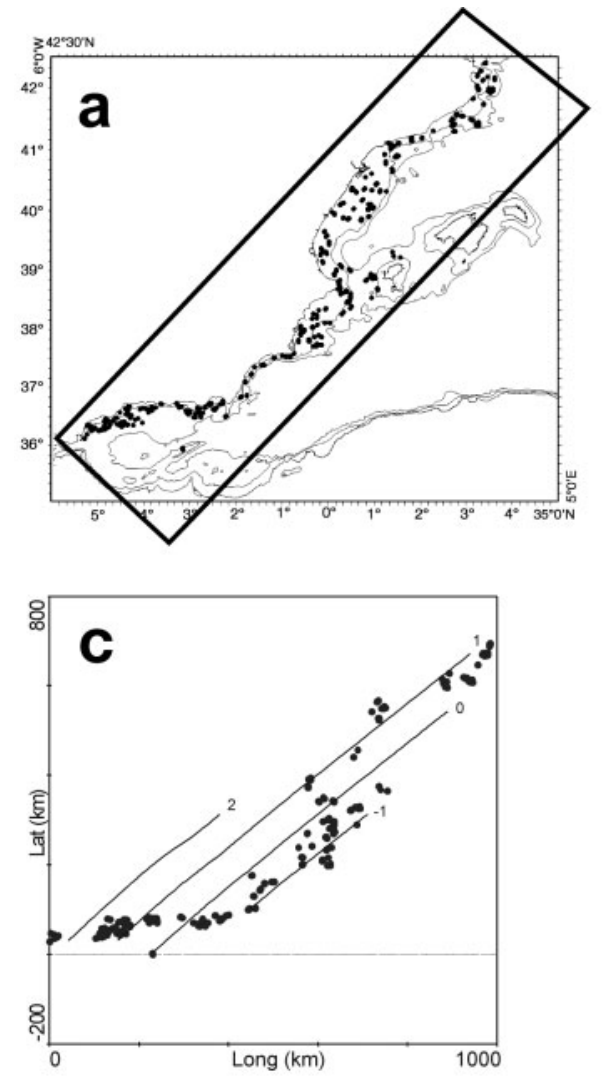

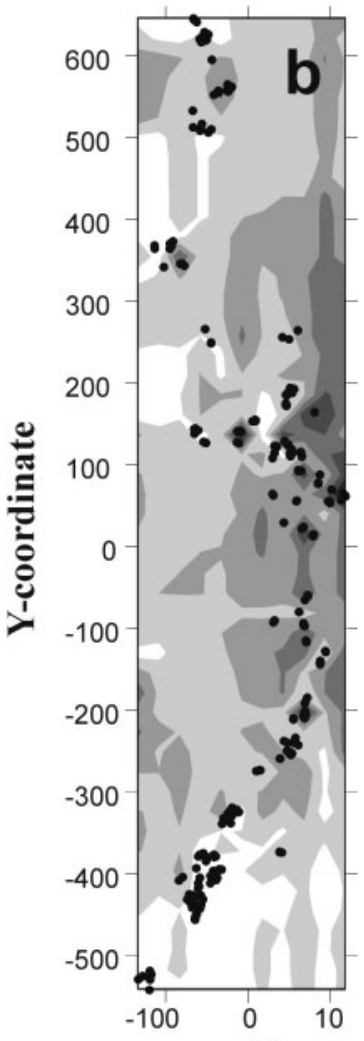

x-coordinate

Fig. 5. Map of the site scores corresponding to the second canonical axis. This axis is depth-independent and highly correlated to the $x$-coordinate. (a) shows the unrotated area mapped in (b), and facilitates the interpretation of the spatial meaning of the $x$-coordinate. Surfaces with similar species composition have similar scores (SamP scores in Canoco language) and are denoted by a grey scale. (c) maps the site scores which are linear combinations of environmental variables (SamE scores). Both maps evidence different species composi-tion at the central zone (Ibiza Channel). Long: longitude; Lat: latitude

zones larger inputs are exploited by a less diverse assemblage. The features of the Balearic Sea (Font et al. 1988, Millot 1992) considered as a transition (sub)basin of the Western Mediterranean could help to understand this phenomenon. Spring-summer conditions exhibit a recurrent flow pattern characterised by eddies in the north of the Ibiza Channel (Pinot et al. 1999). The WIW (Winter Intermediate Water) is deflected to the Continental Current and advected along the Balearic slope. The transport within the eddies stabilises and a substantial volume of WIW could remain trapped in the southwestern basin.

\section{Depth effect}

A vertical split of depth preferences is clear for Plesionika martia (deep waters) and P. heterocarpus (shal- low waters). However, P. gigliolii and P. edwardsi have overlapping depth preferences as well as geographical locations (see above). The latter pair of species display larger body size differences than the former pair. This could be related to the fact that these species may have different feeding habits. Amongspecies differences in diet have been described for $P$. martia, $P$. heterocarpus and $P$. edwardsi (Cartes 1993), and body size has been proposed as a causal factor for such differences (Cartes 1993). Therefore, an overlap in space and depth between $P$. gigliolii and $P$. edwardsi could be related to differences in feeding habits.

A depth split between juveniles and adults has been previously reported for some species (Company \& Sardà 1997, Carbonell \& Abelló 1998). The results presented here expand the scope to all 4 of the species studied (Fig. 4).

Nepheloid layers are concentrations of supended particles of organic matter detached from the seabed at the shelf break or on the upper continental slope (e.g. Puig \& Palanques 1998, Puig et al. 2001, and op. cit. therein). The presence of these intermediate nepheloid layers (INLs) has been associated with a large juvenile abundance (i.e. 'nurseries'), and higher food availability at INLs would be the cause of increased larval survival (Puig et al. 2001). Unfortunately, we are not able to test such a hypothesis due to the scarcity of data on INL positions along the entire Spanish Mediterranean coastline.

Finally, the results presented here point to 2 applied aspects. First, the clear and general splitting between adults and juvenile demands an explanation because it will be decisive in designing fishing policy programs for sustainable management of deep-water resources. Second, among-zone differences should be considered in the open debate between a single management policy for an extended area, or one general management policy and several rules for local areas.

Acknowledgements. This research is included in the MEDITS-ES project, co-financed by the IEO and DG XIV-UE. The authors also thank the captains, crew and scientists aboard B/O 'Cornide de Saavedra' for assisting with sampling.

\section{LITERATURE CITED}

Bertrand J, Gil de Sola L, Papaconstantinou C, Relini CG, Souplet A (2000) An international bottom trawl survey in the Mediterranean: the Medits programme. In: Bertrands JA, Relini G (eds) Demersal resources in the Mediter- 
ranean, Proc Symp, Pisa, 18-21 March 1998. Actes de Colloques 26, IFREMER. Plouzané, p 76-93

Bertrand JA, Leonori I, Dremiere PY, Cosimi G (2002) Depth trajectory and performance of a trawl used for an international bottom trawl survey in the Mediterranean. Sci Mar 66 (Suppl 2):169-182

Carbonell A, Abelló P (1998) Distribution characteristics of pandalid shrimps (Decapoda: Caridea: Pandalidae) along the western Mediterranean Sea. J Nat Hist 32:1463-1474

Cartes JE (1993) Diets of deep-water pandalid shrimps on the Western Mediterranean slope. Mar Ecol Prog Ser 96:49-61

Cartes JE, Company JB, Maynou F (1994) Deep-water decapod crustacean communities in the Northwestern Mediterranean: influence of submarine canyons and seasons. Mar Biol 120:221-229

Company JB, Sardà F (1997) Reproductive patterns and population characteristics infive deep-water pandalid shrimps in the Western Mediterranean along a depth gradient (150-1100 m). Mar Ecol Prog Ser 148:49-58

Englund E, Sparks A (1988) Geo-EAS user's guide. EPA Report, Las Vegas, NV

Font J, Salat J, Tintore J (1988) Permanent features of the circulation in the Catalan Sea. Oceanol Acta (Spec Issue) 9:51-57

Gerino M, Stora G, Poydenot F, Bourcier M (1995) Benthic fauna and bioturbation on the Mediterranean continental slope: Toulon Canyon. Cont Shelf Res 15:1483-1496

Legendre P, Legendre L (1998) Numerical ecology. Elsevier Science, Amsterdam

Maynou F, Cartes JE (2000) Community structure of bathyal decapod crustaceans off south-west Balearic Islands

Editorial responsibility: Otto Kinne (Editor),

Oldendorf/Luhe, Germany (western Mediterranean): seasonality and regional patterns in zonation. J Mar Biol Assoc UK 80:789-798

Millot C (1992) Are there major differences between the largest mediterranean seas? A preliminary investigation. Bull Inst Oceanogr (Monaco) (Spec) 11:2-25

Pinot JM, Álvarez A, Fernández V, Riera M (1999) The role of winter intermediate waters in the spring-summer circulation of the Balearic Sea 2. A sensitivity numerical study. J Geophys Res 104(C12):29865-29884

Puig P, Palanques A (1998) Nepheloid structure and hydrographic control on the Barcelona continental margin, northwestern Mediterranean. Mar Geol 149(1998):39-54

Puig P, Company JB, Sardà F, Palanques A (2001) Responses of deep-water shrimp populations to intermediate nepheloid layer detachments on the Northwestern Mediterranean continental margin. Deep-Sea Res Part I 48(10): 2195-2207

Roa R, Tapia F (2000) Cohorts in space: geostatistical mapping of the age structure of squat lobster Pleurocodes monodon population off central Chile. Mar Ecol Prog Ser 196:239-251

Rossi L, Costantini ML (2000) Mapping the intra-habitat variation of leaf mass loss rate in a brackish Mediterranean lake. Mar Ecol Prog Ser 203:145-159

ter Braak CJF, Smilauer P (1998) CANOCO reference manual and user's guide to Canoco for Windows: software for Canonical Community ordination (version 4). Microcomputer Power, Ithaca, NY

Zuo Z, Eisma D, Gieles R, Beks J (1997) Accumulation rates and sediment deposition in the northwestern Mediterranean. Deep-Sea Res 44:597-609

Submitted: February 26, 2002; Accepted: November 1, 2002 Proofs received from author(s): January 8, 2003 